\title{
Unipedicular versus bipedicular percutaneous vertebroplasty for osteoporotic vertebral compression fractures: a prospective randomized study
}

\author{
Liang Zhang ${ }^{1}$, Zhongjun Liư ${ }^{2}$, Jingcheng Wang ${ }^{1}$, Xinmin Feng ${ }^{1 *}$, Jiandong Yang ${ }^{1}$, Yuping Tao ${ }^{1}$ and Shengfei Zhang ${ }^{1}$
}

\begin{abstract}
Background: Percutaneous vertebroplasty (PVP) typically involves conventional lower-viscosity cement injection via bipedicular approach. Limited evidence is available comparing the clinical outcomes and complications in treating osteoporotic vertebral compression fractures (OVCFs) with PVP using high-viscosity cement through unipedicular or bipedicular approach.

Methods and design: Fifty patients with OVCFs were randomly allocated into two groups adopting unipedicular or bipedicular PVP. The efficacy of unipedicular and bipedicular PVP was assessed by comparing operation time, $X$-ray exposure time, incidence of complications, vertebral height restoration, and improvement of the visual analogue scale (VAS), Oswestry disability index (ODI) and Short Form-36 (SF-36) General Health Survey scores.

Results: The mean operative and exposure time to X-rays in the unipedicular PVP group was less than that of the bipedicular group $(p<0.05)$. No statistically significant differences were observed in the VAS score, ODI score, SF-36 score, cement leakage rate or vertebral height restoration between the two groups ( $p>0.05)$.

Conclusion: Unipedicular and bipedicular PVP are safe and effective treatments for OVCF. Compared with bipedicular PVP, unipedicular PVP entails a shorter surgical time and lower X-ray irradiation.
\end{abstract}

Keywords: Osteoporotic vertebral compression fractures, Unipedicular, Bipedicular, Vertebroplasty

\section{Background}

Osteoporosis is the most common systemic disorder worldwide, characterized by low bone mass, altered bone microarchitecture and increased risk of fragility fracture $[1,2]$. In the European Union, an estimated 22 million women and 5.5 million men are afflicted with osteoporosis, with an annual cost of fractures related to osteoporosis pegged at euro 37.0 billion, expected to increase by $25 \%$ in 2025 [3]. The most common fragility fractures associated with osteoporosis are vertebral compression fractures (OVCFs), affecting $25 \%$ of postmenopausal women and more than 200 million individuals

\footnotetext{
*Correspondence: 17374769@qq.com

'Department of Orthopedics, Clinical Medical College of Yangzhou University, Subei People's Hospital of Jiangsu Province, No.98 Nantong West Road, Yangzhou 225001, China

Full list of author information is available at the end of the article
}

worldwide [4]. OVCFs cause substantial pain and deformity, leading to disability and poor quality of life. The usual treatment of OVCF includes analgesics, external braces and physical therapy. However, a few patients may still complain of severe pain after conservative treatments and even show progressive collapse of the vertebral body and kyphosis with or without neurological deficit [5-7]. Various techniques of vertebral body augmentation have been developed in an effort to treat these refractory cases. Over the past few decades, percutaneous vertebroplasty (PVP) has gained popularity as the optimal treatment modality for OVCF. PVP provided rapid pain relief and longlasting effects in a large case series and nonrandomized controlled trails $[6,8,9]$. Although relatively safe and effective, PVP is associated with complications including cement leakage, soft tissue damage, pedicle fracture, nerve injury and spinal epidural hematoma $[10,11]$. 
The detection rate of cement leakage ranges from $7 \%$ by $\mathrm{x}$-ray to $82 \%$ using computed tomography (CT) [12]. While most leakages are asymptomatic, serious complications of nerve root or spinal cord compression and pulmonary embolism cannot be ruled out $[10,11,13]$. Reducing cement leakage using vertebral venography, gel-foam embolization, and kyphoplasty resulted in inconclusive outcomes [8, 14, 15]. High-viscosity cements have been demonstrated to effectively reduce the risk of epidural and venous cement leakage, thereby improving overall clinical safety [16-19]. The standard technique is typically carried out using a bipedicular approach $[18,19]$. In recent years, unipedicular PVP has been advocated, reducing the operating and radiation exposure time, lowering the risk of cement leakage and complications caused by vertebral pedicle puncture. In addition, it increased the costeffectiveness of the procedure as well as clinical efficacy. To compare the efficacy and adverse effects of unipedicular PVP with that of bipedicular PVP using high-viscosity cement, we conducted a prospective randomized and controlled study in our hospital. To the best of our knowledge, there has been no such report published until now.

\section{Methods}

\section{Patients and controls}

The Institutional Review Board of our hospital (Clinical Hospital of Yangzhou University Institutional Review Board Committee) approved this study, and patients provided informed consent prior to the study. From November 2010 to October 2012, a total of 58 patients with OVCF adopting PVP with high-viscosity bone cement were included in our study. Clinical indications for vertebral augmentation were regularly confirmed by an interdisciplinary team of oncologists, radiation oncologists, spine surgeons, and interventional radiologists prior to the intervention.

Study inclusion criteria were as follows: (1) age over 50 years; (2) single-level OVCF; (3) focal back pain in the midline unresponsive to at least 8 weeks of conservative treatments; (4) back pain related to the location of the OVCF on magnetic resonance imaging (MRI) radiographs; (5) presence of an apparent bone edema in the fractured vertebra on T2-weighted short-tau inversion recovery sequences (STIR) in MRI; (6) bilateral pedicle intact without fracture; and (7) decreased bone mineral density ( $\mathrm{T}$ scores $<-1$ ). We excluded patients with (1) vertebral compression fracture due to causes other than osteoporosis; (2) spinal cord compression or stenosis of the vertebral canal $>30 \%$ of the local canal diameter; (3) neurologic deficits; (4) incurable bleeding disorders; (5) systemic or local spine infections; (6) severe comorbidity of heart, liver, kidney, and lung intolerance to surgery.

All eligible patients were assigned a serial number according to the consecutive sequence of hospitalization and allocated to group $\mathrm{U}$ (using unipedicular approach) or group B (using bipedicular approach) randomly by computer. The study population consisted of 24 patients in group $U$ ( 8 male and 16 female, mean age $=69.2$ years, range $=52-81$ years) and 26 patients in the group $B(10$ male and 16 female, mean age $=70.5$ years, range $=57-83$ years). All procedures were performed by the same surgeon.

\section{Surgical technique}

All surgical procedures were conducted under general anesthesia, with the patient in prone position on a carbonfiber radiolucent, $\mathrm{C}$-arm table. After localizing the fractured vertebra using fluoroscopy, the surgeon placed overlapping palm on the vertebral spinous process to push ventrally slowly and partially reduce the fractured vertebra. A small skin puncture was made approximately $2.5 \mathrm{~cm}$ off of mid-line. The introducer was directed to the junction of the middle and anterior $1 / 3$ of the affected vertebral body under $\mathrm{C}$-arm fluoroscopic guidance. Once the needle was in the optimal position, the high-viscosity polymethylmethacrylate (PMMA) bone cement was injected with a specially designed delivery system (Disc-O-Tech Medical Technologies Ltd. Herzliya, Israel) according to the manufacturer's specifications. The injection procedure was carefully controlled under strict lateral fluoroscopy and stopped whenever epidural or paravertebral opacification was observed or the cement reached the dorsal quarter of the vertebral body.

\section{Outcome measurements}

We emphasized both surgical complications and clinical outcomes in both groups three days and two years after surgery. Outcome measures included: (1) surgery time (from skin incision to suturing), exposure time to the X-ray C-arm machine and cement dosage; (2) Visual Analog Scale (VAS) score for analgesic efficacy evaluation; (3) Oswestry Disability Index (ODI) for functional assessment; (4) Short Form-36 General Health Survey (SF-36) for quality of life evaluation: Physical Component Summary (PCS) and the Mental Component Summary (MCS); (5) complications including cement leakage and adjacent vertebral fractures; and (6) radiographic outcomes including anterior and middle vertebral body height variation, (calculated by fractured vertebral body height/normal vertebral body height $x$ $100 \%)$. Normal heights of the vertebrae were defined as the mean of the equivalent values for the adjacent superior and inferior non-fractured vertebrae. Anterior and middle vertebral height was defined as the distance between the upper and lower endplates at the anterior and middle vertebral body wall and in the center of the vertebral body.

\section{Statistical analysis}

Data were presented as the mean \pm standard deviation. The SPSS for Windows Version 13.0 (SPSS, Chicago, IL) was 
used for the analysis. Statistical analysis was performed by an independent statistician blinded to the surgical procedures. The statistical significance of pre- and post-surgical clinical and radiographic data within each group and between groups was evaluated using independent $t$-test and chi-square test. The difference of cement leakage between two groups was assessed using the $\chi 2$ test. The level of statistical significance was set at $\mathrm{p}<0.05$.

\section{Results}

\section{Surgical parameters}

The mean surgery time was $41.2 \pm 5.2 \mathrm{~min}$ in group $\mathrm{U}$, which was shorter than $55.7 \pm 7.3 \mathrm{~min}$ in group B ( $p<$ 0.001 ) (Table 1). Patients were exposed to X-rays $33.7 \pm$ $5.2 \mathrm{~min}$ in group $\mathrm{U}$ and $46.5 \pm 6.6 \mathrm{~min}$ in group $\mathrm{B}$, and the difference was statistically significant $(p<0.001)$ (Table 1). The bone cement volume was $3.1 \pm 0.4 \mathrm{~mL}$ in group $\mathrm{U}$ and $5.0 \pm 0.5 \mathrm{~mL}$ in group $\mathrm{B}$, and this difference was also statistically significant $(p<0.001)$ (Table 1$)$.

\section{Clinical outcomes}

There was no difference between the 2 groups in terms of the pre-operative VAS, ODI, PCS and MCS measurements (Table 2). Patients in both groups exhibited marked and sustained pain reduction, function and quality of life improvement. Significant statistical differences were found before and after operation in terms of VAS, ODI and SF-36 scores (Table 2). However, no statistical differences were found 3 days or 2 years postoperatively between the 2 groups in terms of the clinical outcomes (Table 2).

\section{Radiological outcomes}

There were no surgical complications in either group. The bone cement leakage rate was $20.8 \%$ (5 of 24) in the group U and $34.6 \%$ (9 in 26) in group B, which was not a statistically significant difference $(\mathrm{p}=0.28)$. Of the 5 bone cement leakages in group $\mathrm{U}$, one occurred into the anterior vertebra, 2 were leakages into the disc and another 2 were venous leaks. Of the 9 bone cement

Table 1 Surgical parameters of the studied population

\begin{tabular}{llll}
\hline & Group U & Group B & p-value \\
\hline & $\mathrm{N}=24$ & $\mathrm{~N}=26$ & \\
Male/female & $5: 19$ & $8: 18$ & $0.42^{\mathrm{a}}$ \\
Age (years) & $71.7 \pm 7.5$ & $72.1 \pm 6.0$ & $0.84^{\mathrm{b}}$ \\
Operative time & $41.2 \pm 5.2$ & $55.7 \pm 7.3$ & $0.001^{\mathrm{b}}$ \\
Exposed to X-rays time & $33.7 \pm 5.2$ & $46.5 \pm 6.6$ & $0.001^{\mathrm{b} *}$ \\
Injected cement volume & $3.1 \pm 0.4$ & $5.0 \pm 0.5$ & $0.001^{\mathrm{b} *}$ \\
Cement leakage & 5 & 9 & $0.28^{\mathrm{a}}$ \\
\hline
\end{tabular}

Group U: PVP through unipedicular approach

Group B: PVP through bipedicular approach

${ }^{\text {a }}$ Pvalues for between-group comparison were determined by $X^{2}$ tests

${ }^{b}$ Pvalues for between-group comparison were determined by $t$ tests

*Statistically significant ( $p$ value <0.05)
Table 2 Clinical outcomes of the two groups

\begin{tabular}{lllll}
\hline Time & Parameter & Group U & Group B & p-value \\
\hline \multirow{2}{*}{ Preoperative } & VAS & $8.1 \pm 1.0$ & $8.0 \pm 1.2$ & 0.78 \\
& ODI & $45.2 \pm 5.1$ & $43.2 \pm 4.1$ & 0.13 \\
& PCS & $31.6 \pm 4.9$ & $29.1 \pm 3.7$ & 0.13 \\
Three days & MCS & $31.2 \pm 3.9$ & $32.1 \pm 3.1$ & 0.41 \\
postoperative & & $2.6 \pm 0.8^{*}$ & $2.5 \pm 0.9 \dagger$ & 0.73 \\
& ODI & $27.3 \pm 4.2^{*}$ & $26.1 \pm 3.4 \dagger$ & 0.28 \\
& PCS & $44.8 \pm 5.2^{*}$ & $42.6 \pm 4.5 \dagger$ & 0.11 \\
Two years & MCS & $41.0 \pm 3.8^{*}$ & $40.1 \pm 4.2 \dagger$ & 0.43 \\
postoperative & VAS & $2.1 \pm 0.9^{*}$ & $2.1 \pm 0.7 \dagger$ & 0.97 \\
& & & & \\
& ODI & $19.9 \pm 4.6^{*}$ & $18.9 \pm 2.6 \dagger$ & 0.26 \\
& PCS & $52.9 \pm 3.7^{*}$ & $52.8 \pm 5.5 \dagger$ & 0.93 \\
& MCS & $45.7 \pm 3.8^{*}$ & $45.3 \pm 3.7 \dagger$ & 0.74 \\
\hline
\end{tabular}

Group U: PVP through unipedicular approach

Group B: PVP through bipedicular approach

VAS visual analogue scale; ODI oswestry disability index;

PCS physical component summary; MCS mental component summary

$P$ values for between-group comparison were determined by t tests

${ }^{*} \mathrm{P}=0.000$, compared to Preoperative outcomes in Group $U$

$+\mathrm{P}=0.000$, compared to Preoperative outcomes in Group B

leakages in group B, 3 occurred into the disc, one into paravertebral, 2 into epidural, and another 3 were venous leaks. However, no clinical symptoms were identified due to leakage and no special treatment was necessary.

The anterior and middle vertebral heights of the fractured vertebra before surgery showed no significant diffeence between the 2 groups (Table 3). Similarly, no statistical difference was found 3 days later or even after 2 years. However, significant statistical differences were found before and after the operation in terms of the anterior and middle vertebral heights of the fractured vertebra (Table 3).

\section{Discussion}

PVP is the optimal treatment for OVCF and provides rapid pain relief and stabilization of the fractured vertebral bodies $[8,20,21]$. Although cement leakage is reported as high as $73 \%$ for both PVP types, most leakages remain clinically asymptomatic, and even small quantities of leakage may have a significant clinical impact [12]. The three factors that may influence the cement flow into and out of the vertebral body include: bone and fracture-related parameters, cement properties, and injection methods. Although fracture morphology is impossible to control, the cement properties and method of injection may be manipulated to ultimately decrease the complication rate.

Viscosity of bone cement used in PVP is hypothesized to influence the outcome of the procedure in various 
Table 3 Radiological outcomes of the two groups

\begin{tabular}{|c|c|c|c|c|}
\hline Time & Parameter & Group U & Group B & $p$-value \\
\hline & & $N=24$ & $N=26$ & \\
\hline \multirow[t]{4}{*}{ Preoperative } & Anterior vertebral body & $41.8 \pm 7.5$ & $42.9 \pm 8.0$ & 0.63 \\
\hline & height variation, $\%$ & & & \\
\hline & Middle vertebral body & $46.9 \pm 5.4$ & $47.3 \pm 6.1$ & 0.81 \\
\hline & height variation, \% & & & \\
\hline \multirow{4}{*}{$\begin{array}{l}\text { Three days } \\
\text { postoperative }\end{array}$} & Anterior vertebral body & $56.3 \pm 6.4^{*}$ & $59.0 \pm 5.2 \dagger$ & 0.11 \\
\hline & height variation, $\%$ & & & \\
\hline & Middle vertebral body & $58.5 \pm 4.8^{*}$ & $59.6 \pm 5.5 \dagger$ & 0.44 \\
\hline & height variation, $\%$ & & & \\
\hline \multirow{4}{*}{$\begin{array}{l}\text { Two years } \\
\text { postoperative }\end{array}$} & Anterior vertebral body & $53.0 \pm 5.9^{*}$ & $55.6 \pm 5.3 \dagger$ & 0.11 \\
\hline & height variation, $\%$ & & & \\
\hline & Middle vertebral body & $55.4 \pm 5.0^{*}$ & $56.8 \pm 5.4 \dagger$ & 0.34 \\
\hline & height variation, \% & & & \\
\hline
\end{tabular}

Group U: PVP through unipedicular approach

Group B: PVP through bipedicular approach

$P$ values for between-group comparison were determined by $t$ tests

${ }^{*} \mathrm{P}=0.000$, compared to Preoperative outcomes in Group $U$

$+P=0.000$, compared to Preoperative outcomes in Group B

ways. Increased viscosity leads to increased circularity of the cement cloud and decreased spreading distance [22, 23]. PVP with high-viscosity cement offers all the advantages, especially minimizing the risk of cement leakage and significantly increasing the clinical safety [22, 24]. In the PVP procedure, unipedicular approach is being increasingly used to treat OVCF, to reduce medical costs and X-ray exposure, as well as for better clinical efficacy $[25,26]$. In our prospective, randomized study, both unipedicular and bipedicular PVP group achieved satisfactory results and patients'clinical outcome parameters were significantly improved and consistent compared to pre-surgical levels. The improvement in the clinical outcome and recovery of vertebral heights were not significantly different between the two groups under the strict inclusion criteria.

In theory, bipedicular PVP shows increased incidence of complications such as tissue trauma, nerve injury and pedicle fractures. However, in our study, no pedicle fractures or nerve damage occurred in either group. The complications resulting largely from poor operative technique can be minimized at the operator level.

Some clinical studies have positively correlated the bone cement injection volume with the leakage of bone cement [27]. In theory, the risk of bone cement leakage is also twice that of unipedicular approach. However the difference in cement leakage rates between unipedicular and bipedicular PVP with conventional viscosity cement was not statistically significant [28-31]. The cement leakages in PVP with high-viscosity cement are still unknown. A larger volume of injected cement through the bipedicular approach is also more likely to result in extravasations. The most common cement leakage was venous leakage $(6.1 \%)$ and intradiscal leakage $(8.2 \%)$ in PVP with high-viscosity Confidence bone cement reported by Anselmetti et al. [22]. However, the leakage rate was almost as high as $47 \%$ reported by Georgy et al. [18]. The cement leakage rates in the above two studies were far different. By comparison, we found that the biggest difference may be the methods adopted (unipedicular approach by Anselmetti vs. bipedicular approach by Georgy) and cement leakages detected (CT by Anselmetti vs. plain film by Georgy). CT is now regarded as the gold standard to assess cement leakage [12]. Whether the lower cement leakage rate reported by Anselmetti was due to the different PVP is unclear. In this study, the cement leakage rates of both groups were lower but not statistically significant compared with PVP using standard low-viscosity cement. The results suggested that increased bone cement injection did not result in increased bone cement leakage rate, which may be attributed to the nature of high-viscosity bone cement itself.

The X-ray exposure and operation time of unipedicular approach were significantly reduced. Unipedicular PVP lessens the radiation dose, thereby reducing health risks to the medical staff performing the PVP. If $5 \%$ of all vertebral compression fractures in the United States were treated by unipedicular kyphoplasty, instead of bipedicular kyphoplasty, the savings would be $>\$ 32$ million per year [32]. Thus, our results support the concept that the unipedicular technique is a faster, costeffective alternative that still provides a comparable correction of spinal deformity to the bipedicular technique. The unipedicular technique is specifically indicated for the elderly, or patients who have more than one affected vertebra.

The limitations of our study are related to the relatively small sample size and the follow-up of only three days and two years. We also failed to perform a direct comparison of vertebroplasty with kyphoplasty using high-viscosity cement. Further study using a larger sample size and longer or more frequent follow-ups are needed to confirm our results.

\section{Conclusion}

Unipedicular and bipedicular PVP are safe and effective treatments for OVCF. Although the pain relief and improved physical ability were comparable with either technique, we encourage the use of the unipedicular approach as the preferred surgical technique for treatment of OVCFs due to less operation time, limited X-ray exposure, minimal cement introduction and extravasation. 


\section{Abbreviations}

PVP: Percutaneous vertebroplasty; OVCFs: Osteoporotic vertebral compression fractures; VAS: Visual analogue scale; ODI: Oswestry disability index; SF-36: Short Form-36; MRI: Magnetic resonance imaging; PMMA: polymethylmethacrylate.

\section{Competing interests}

The authors declare that they have no competing interests.

\section{Authors' contributions}

LZ participated in study design/data analysis and drafted the manuscript, and acted as first author. ZJL participated in the design of the study, analyzed the radiographic and functional measurements. XMF participated in the design of the study and carried out the operation. JCW assisted with funding, supervised the study design and data analysis, revised the manuscript and acted as the corresponding author. YPT assisted with clinical examinations and surgery. JDY participated in the design of the study and coordinated the research groups. SFZ participated in data collection and interpretation. All authors read and approved the final manuscript.

\section{Acknowledgements}

The authors would like to thank Pro Yongxiang Wang and Dr Jun Cai for the technical support and for proof-reading the original manuscript. The authors wish to thank Jijun Huang and Zhiqiang Zhang for their assistance with translation. We also thank all study participants. Finally, we thank all those who provided medical writing services on behalf of Shanghai BIOON Info-tech Co.Ltd

\section{Funding}

This work was funded by National Natural Science Foundation for Young Scholars of China (Grant No. 81401830) as well as Natural Science Foundation for Young Scholars of Jiangsu Province, China (Grant No. BK 20140496).

\section{Author details}

${ }^{1}$ Department of Orthopedics, Clinical Medical College of Yangzhou University, Subei People's Hospital of Jiangsu Province, No.98 Nantong West Road, Yangzhou 225001, China. ${ }^{2}$ Department of Orthopaedics, Peking University Third Hospital, Beijing 100191, China.

\section{Received: 2 December 2014 Accepted: 18 May 2015}

\section{Published online: 14 June 2015}

\section{References}

1. Litwic A, Cooper C, Dennison E. Osteoporosis therapies in 2014. Panminerva Med. 2014;56:273-83.

2. Appelman-Dijkstra NM, Papapoulos SE. Novel approaches to the treatment of osteoporosis. Best Pract Res Clin Endocrinol Metab. 2014;28:843-57.

3. Hernlund E, Svedbom A, Ivergard M, Compston J, Cooper C, Stenmark J, et al. Osteoporosis in the European Union: medical management, epidemiology and economic burden. A report prepared in collaboration with the International Osteoporosis Foundation (IOF) and the European Federation of Pharmaceutical Industry Associations (EFPIA). Arch Osteoporos. 2013;8:136.

4. Johnell O, Kanis JA. An estimate of the worldwide prevalence and disability associated with osteoporotic fractures. Osteoporos Int. 2006;17:1726-33.

5. Chen D, An ZQ, Song S, Tang JF, Qin H. Percutaneous vertebroplasty compared with conservative treatment in patients with chronic painful osteoporotic spinal fractures. J Clin Neurosci. 2014;21:473-7.

6. Liu J, Li X, Tang D, Cui X, Yao M, Yu P, et al. Comparing pain reduction following vertebroplasty and conservative treatment for osteoporotic vertebral compression fractures: a meta-analysis of randomized controlled trials. Pain Physician. 2013;16:455-64.

7. Kim KW, Cho KJ, Kim SW, Lee SH, An MH, Im JH. A nation-wide, outpatient-based survey on the pain, disability, and satisfaction of patients with osteoporotic vertebral compression fractures. Asian Spine J. 2013;7:301-7.

8. Stevenson M, Gomersall T, Lloyd Jones M, Rawdin A, Hernandez M, Dias S, et al. Percutaneous vertebroplasty and percutaneous balloon kyphoplasty for the treatment of osteoporotic vertebral fractures: a systematic review and cost-effectiveness analysis. Health Technol Assess. 2014;18:1-290.

9. Kim JH, Yoo SH. Long-term follow-up of percutaneous vertebroplasty in osteoporotic compression fracture: minimum of 5 years follow-up. Asian Spine J. 2012;6:6-14
10. Nieuwenhuijse MJ, Van Erkel AR, Dijkstra PD. Cement leakage in percutaneous vertebroplasty for osteoporotic vertebral compression fractures: identification of risk factors. Spine J. 2011;11:839-48.

11. Lee MJ, Dumonski M, Cahill P, Stanley T, Park D, Singh K. Percutaneous treatment of vertebral compression fractures: a meta-analysis of complications. Spine (Phila Pa 1976). 2009;34:1228-32.

12. Martin DJ, Rad AE, Kallmes DF. Prevalence of extravertebral cement leakage after vertebroplasty: procedural documentation versus $C T$ detection. Acta Radiol. 2012;53:569-72.

13. Venmans A, Lohle P, Van Rooij W, Verhaar H, Mali WTM. Frequency and outcome of pulmonary polymethylmethacrylate embolism during percutaneous vertebroplasty. Am J Neuroradiol. 2008;29:1983-5.

14. He SC, Teng GJ, Fang W, Deng G, Guo JH, Zhu GY. [Value of intraosseous venography in percutaneous vertebroplasty for treatment of symptomatic vertebral hemangiomas]. Zhonghua Yi Xue Za Zhi. 2010;90:3188-92.

15. Bhatia C, Barzilay Y, Krishna M, Friesem T, Pollock R. Cement leakage in percutaneous vertebroplasty: effect of preinjection gelfoam embolization. Spine (Phila Pa 1976). 2006;31:915-9.

16. Lador R, Liberman S, Ben-Galim P, Dreiangel N, Reitman CA, Hipp JA. A cadaver study to compare vertebral augmentation with a high-viscosity cement to augmentation with conventional lower-viscosity cement. J Spinal Disord Tech. 2013;26:68-73

17. Rapan S, Jovanovic S, Gulan G, Boschi V, Kolarevic V, Dapic T. Vertebroplastyhigh viscosity cement versus low viscosity cement. Coll Antropol. 2010;34:1063-7.

18. Georgy BA. Clinical experience with high-viscosity cements for percutaneous vertebral body augmentation: occurrence, degree, and location of cement leakage compared with kyphoplasty. AJNR Am J Neuroradiol. 2010;31:504-8.

19. Nieuwenhuijse MJ, Muijs SP, van Erkel AR, Dijkstra SP. A clinical comparative study on low versus medium viscosity polymethylmetacrylate bone cement in percutaneous vertebroplasty: viscosity associated with cement leakage. Spine (Phila Pa 1976). 2010;35:E1037-44.

20. Huang H, He S, Fang W, Zhu H, Guo J, Deng G, et al. [Percutaneous vertebroplasty for treatment of painful osteoporotic vertebral compression fractures: a retrospective analysis of clinical efficacy]. Zhonghua Yi Xue Za Zhi. 2014:94:2119-22.

21. Voormolen MH, Mali WP, Lohle PN, Fransen H, Lampmann LE, van der Graaf $Y$, et al. Percutaneous vertebroplasty compared with optimal pain medication treatment: short-term clinical outcome of patients with subacute or chronic painful osteoporotic vertebral compression fractures. The VERTOS study. AJNR Am J Neuroradiol. 2007;28:555-60.

22. Anselmetti GC, Zoarski G, Manca A, Masala S, Eminefendic H, Russo F, et al. Percutaneous vertebroplasty and bone cement leakage: clinical experience with a new high-viscosity bone cement and delivery system for vertebral augmentation in benign and malignant compression fractures. Cardiovasc Intervent Radiol. 2008;31:937-47.

23. Baroud G, Crookshank M, Bohner M. High-viscosity cement significantly enhances uniformity of cement filling in vertebroplasty: an experimental model and study on cement leakage. Spine. 2006;31:2562-8.

24. Ruger M, Schmoelz W. Vertebroplasty with high-viscosity polymethylmethacrylate cement facilitates vertebral body restoration in vitro. Spine (Phila Pa 1976). 2009;34:2619-25.

25. Chen C, Bian J, Zhang W, Zhao C, Wei H. Unilateral Versus Bilateral Vertebroplasty for Severe Osteoporotic Vertebral Compression Fractures. J Spinal Disord Tech. 2014;27(8):E301-4.

26. Gao W, Mi S, Gao J. [Percutaneous vertebroplasty to treat osteoporotic vertebral compression fractures combined with intravertebral clefts by unilateral approach]. Zhongguo Xiu Fu Chong Jian Wai Ke Za Zhi. 2012;26:1330-5.

27. Kaufmann TJ, Trout AT, Kallmes DF. The effects of cement volume on clinical outcomes of percutaneous vertebroplasty. AJNR Am J Neuroradiol. 2006;27:1933-7.

28. Wang Z, Wang G, Yang H. Comparison of unilateral versus bilateral balloon kyphoplasty for the treatment of osteoporotic vertebral compression fractures. J Clin Neurosci. 2012;19:723-6.

29. Li LH, Sun TS, Liu Z, Zhang JZ, Zhang Y, Cai YH, et al. Comparison of unipedicular and bipedicular percutaneous kyphoplasty for treating osteoporotic vertebral compression fractures: a meta-analysis. Chin Med J (Engl). 2013;126:3956-61.

30. Rebolledo BJ, Gladnick BP, Unnanuntana A, Nguyen JT, Kepler CK, Lane JM. Comparison of unipedicular and bipedicular balloon kyphoplasty for the 
treatment of osteoporotic vertebral compression fractures: a prospective randomised study. Bone Joint J. 2013;95-B:401-6.

31. Chen C, Wei H, Zhang W, Gu Y, Tang G, Dong R, et al. Comparative study of kyphoplasty for chronic painful osteoporotic vertebral compression fractures via unipedicular versus bipedicular approach. J Spinal Disord Tech. 2011;24:E62-5.

32. Steinmann J, Tingey CT, Cruz G, Dai Q. Biomechanical comparison of unipedicular versus bipedicular kyphoplasty. Spine (Phila Pa 1976). 2005;30:201-5

Submit your next manuscript to BioMed Central and take full advantage of:

- Convenient online submission

- Thorough peer review

- No space constraints or color figure charges

- Immediate publication on acceptance

- Inclusion in PubMed, CAS, Scopus and Google Scholar

- Research which is freely available for redistribution 